\title{
A case of Wernicke's encephalopathy following complicated laparoscopic pylorus-preserving pancreaticoduodenectomy
}

\author{
Ji Su Kim¹, Seoung Yoon Rho, ${ }^{1,2}$, Ho Kyoung Hwang ${ }^{1,2}$, Woo Jung Lee ${ }^{1,2}$, and Chang Moo Kang ${ }^{1,2}$ \\ ${ }^{1}$ Division of Hepatobiliary and Pancreatic Surgery, Yonsei University College of Medicine, \\ ${ }^{2}$ Pancreatobiliary Cancer Center, Yonsei Cancer Center, Severance Hospital, Seoul, Korea
}

\begin{abstract}
Laparoscopic pylorus-preserving pancreaticoduodenectomy (PPPD)/ pancreaticoduodenectomy (PD) is cautiously regarded as a safe and effective approach in well-selected patients with periampullary cancer. However, postoperative pancreatic fistula (POPF), delayed gastric emptying (DGE), postoperative bleeding, and sepsis and detrimental complications that can follow PPPD/PD. These complications can result in poor oral intake for a significant period of nothing per oral (NPO) or deterioration of long-term function. A 65-year-old man underwent laparoscopic PPPD for ampulla of vater (AoV) cancer. After surgery, He experienced POPF, DGE, Postoperative bleeding and these complications result in poor oral intake for one month. Approximately 50 days after surgery, an abrupt confused state was noted. He had horizontal nystagmus and ataxia. Abnormal Brain magnetic resonance imaging tomography findings detected in the bilateral medial thalami, dorsal midbrain, and medulla. The association of confusion, ataxia, and horizontal nystagmus along with poor oral intake and the MRI findings suggested acute Wernicke's encephalopathy. After thiamine therapy, He recovered completely. Wernicke's encephalopathy is very rare, but it can progress coma and even death. Therefore, Wernicke's encephalopathy needs to be considered in patients with complicated PPPD/PD associated with malnutrition. (Ann Hepatobiliary Pancreat Surg 2019;23:295-299)
\end{abstract}

Key Words: Wernicke's encephalopathy; PPPD; PD; Thiamine deficiency

\section{INTRODUCTION}

Pylorus-preserving pancreaticoduodenectomy (PPPD)/ pancreaticoduodenectomy (PD) is a commonly-known, safe, standardized surgical procedure performed on patients with periampullary cancer. Laparoscopic PPPD/PD is cautiously regarded as a safe and effective approach in well-selected patients with periampullary cancer.

However, the complication rate for PPPD/PD is high (delayed gastric emptying (DGE) 45-50\%, postoperative pancreatic fistula (POPF) $15-20 \%$, biliary fistula $4-5 \%$, intra-abdominal hemorrhage 3-5\%, UGI hemorrhage 3-5\%, etc.), and related surgical mortality is reported to be $1-3 \%{ }^{1}$ Furthermore, POPF, DGE, postoperative bleeding, and sepsis are detrimental complications that can follow PPPD/ PD. In recent years, most patients have been able to recover due to development of new surgical techniques, in- terventional radiotherapy, antibiotics, and nutritional support. Nevertheless, these complications can result in poor oral intake for a significant period of nothing per oral (NPO) or deterioration of long-term function. Proper management is important for patient recovery following complicated PPPD/PD.

We report a case of Wernicke's encephalopathy (WE) in a patient with ampulla of vater $(\mathrm{AoV})$ cancer with persistent poor oral intake and POPF-grade $\mathrm{C}$ after laparoscopic PPPD along with a review of literature.

\section{CASE}

A 65-year-old male underwent laparoscopic PPPD for AoV cancer. During laparoscopic resection, enlarged lymph nodes around peripancreatic lesions were noted and included in the surgical specimen. The remnant pancreas

Received: December 4, 2018; Revised: April 20, 2019; Accepted: April 20, 2019

Corresponding author: Chang Moo Kang

Division of Hepatobiliary and Pancreatic Surgery, Department of Surgery, Yonsei University College of Medicine, Ludlow Faculty Building, 50 Yonsei-ro, Seodaemun-gu, Seoul 03722, Korea

Tel: +82-2-2228-2100, Fax: +82-2-313-8289, E-mail: cmkang@yuhs.ac

Copyright (C) 2019 by The Korean Association of Hepato-Biliary-Pancreatic Surgery

This is an Open Access article distributed under the terms of the Creative Commons Attribution Non-Commercial License (http://creativecommons.org/ licenses/by-nc/4.0) which permits unrestricted non-commercial use, distribution, and reproduction in any medium, provided the original work is properly cited. Annals of Hepato-Biliary-Pancreatic Surgery - pISSN: 2508-5778 - elSSN: 2508-5859 
was noted to be friable and crunch with a $5 \mathrm{~mm}$-sized pancreatic duct. Laparoscopic duct-to-mucosa anastomosis (7 interrupted sutures) for pancreaticojejunostomy with a short stent was performed. The total operation duration was 392 minutes, and the estimated intraoperative blood loss was $150 \mathrm{cc}$. The patient did not receive an intraoperative transfusion.

In the postoperative period, He had POPF. The drain was removed on postoperative day 16 . The patient was expected to go home on postoperative day 21 . However, he experienced postoperative hemorrhage and underwent embolization around the common hepatic artery, stump of the gastroduodenal artery (GDA), and the proper hepatic artery from bleeding at the GDA stump. Subsequently, additional percutaneous drain catheters were inserted for multiple intra-abdominal hematomas and abscesses, and broad-spectrum antibiotics were given. Initially we thought that a grade A-POPF had developed. But He finally diagnosed a grade C-POPF. He was temporarily admitted to the intensive care unit (ICU) and then transferred to the general ward after his vital signs were stable. During the recovery period, the patient suffered repeated nausea and vomiting, and poor oral intake persisted for one month after surgery. Parenteral nutrition and poor oral intake persisted.

Approximately 50 days after surgery, an abrupt confused state was noted. On neurological examination, the patient was awake but disorientated to people, location, and time. A short-memory deficit was also found. The pupils were equal and reactive to light. Motor strength was normal. There were no focal neurological signs or pathological reflexes other than a few hand tremors. However, he had horizontal nystagmus and ataxia. His Nutritional re-assessment was performed at the time of his mental change (Table 1).

Brain magnetic resonance imaging (MRI) tomography showed a symmetrically distributed, abnormal, hyperintense signal on fluid-attenuated inversion recovery and T2-weighted imaging scans in the medial thalami, dorsal midbrain, and medulla (Fig. 1).

The association of confusion, ataxia, and horizontal nystagmus along with poor oral intake and the MRI findings suggested acute WE. The patient's serum thiamine level was $2.3 \mathrm{ug} / \mathrm{dl}$, which is in the lower normal range (reference range, 2.0-7.2 ug/dl). Administration of thiamine (500
Table 1. Nutritional assessment at diagnosis and the time of mental change

\begin{tabular}{lccc}
\hline & $\begin{array}{c}\text { Initial } \\
\text { diagnosis }\end{array}$ & $\begin{array}{c}\text { At the time of } \\
\text { mental change }\end{array}$ & $\begin{array}{c}\text { Reference } \\
\text { range }\end{array}$ \\
\hline Body weight $(\mathrm{kg})$ & 65 & 55 & \\
BMI $\left(\mathrm{kg} / \mathrm{m}^{2}\right)$ & 23.03 & 19.49 & \\
Protein $(\mathrm{g} / \mathrm{dl})$ & 6.5 & 5.9 & $6-8.0$ \\
Albumin $(\mathrm{g} / \mathrm{dl})$ & 3.7 & 2.4 & $3.3-5.3$ \\
Cholesterol $(\mathrm{mg} / \mathrm{dl})$ & 105 & 97 & $142-240$ \\
Potassium $(\mathrm{mmol} / \mathrm{L})$ & 3.8 & 5.0 & $3.5-5.5$ \\
Calcium $(\mathrm{mg} / \mathrm{dl})$ & 9.1 & 8.6 & $8.5-10.5$ \\
Phosphorus $(\mathrm{mg} / \mathrm{dl})$ & 3.1 & 4.3 & $2.5-4.2$ \\
Magnesium $(\mathrm{mg} / \mathrm{dl})$ & 1.54 & 1.42 & $1.09-1.46$ \\
\hline
\end{tabular}

mg daily, intravenously) was initiated and resulted in rapid improvement of his condition, and the symptoms completely subsided after 14 days of treatment. He was discharged from the hospital on postoperative day 73 with a prescription for vitamin B complex and was advised to watch his diet. He is now in good condition (about 3 months postoperatively), and planned for postoperative adjuvant chemotherapy.

\section{DISCUSSION}

\section{Literature review}

Using the PubMed database, we identified seven additional patients who suffered from WE following pancreaticoduodenectomy from seven reports. The clinical characteristics of all seven cases are summarized in Table 2 . Patient age ranged from 27 to 68 years (median age, 47 years), and there were 5 men (71.4\%) and 2 women (28.6\%). One patient (14.3\%) had confirmed chronic alcohol abuse, while the other cases denied a history of abuse, or it was not specifically mentioned. In most cases, there was a factor exacerbating acute WE, such as poor oral intake, pneumonia, or intestinal obstruction. However, it is interesting to note that WE can occur even in the late postoperative period following PD. For instance, the patients in cases one and four experienced an uneventful recovery and were found to have WE a few years after surgery. However, patients with postoperative complications, such as infection and hemorrhage as in cases 2, 3, 5 , 6, and 8, were diagnosed with WE within days or weeks after surgery, which prolonged the length of hospital stay, as in the present case. However, there were many 

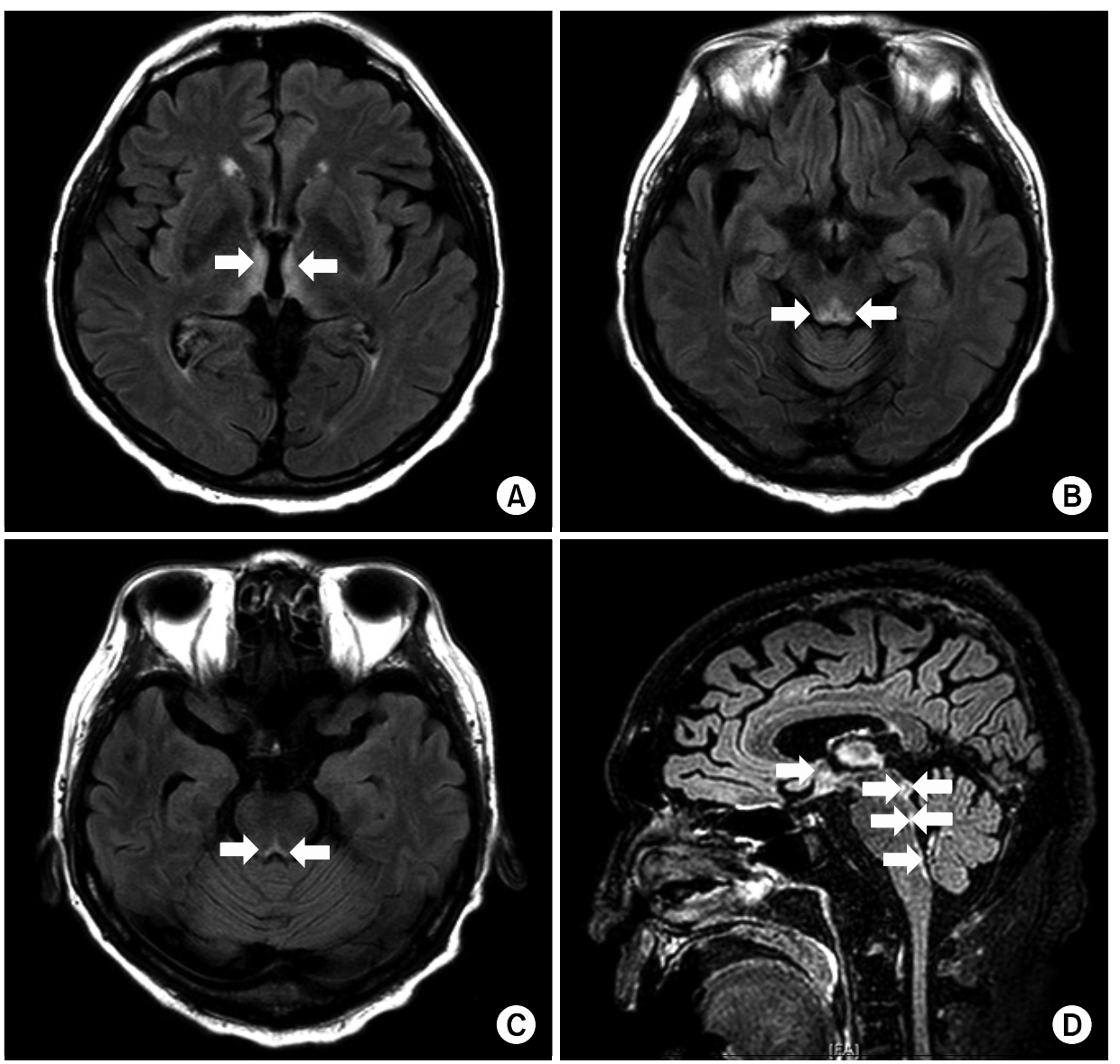

Fig. 1. Fluid-attenuated inversion recovery-weighted axial (A-C) and sagittal (D) magnetic resonance imaging scans showed abnormal, symmetrical, hyperintense signal (arrows) in the bilateral medial thalami, dorsal midbrain, and medulla.

Table 2. Summary of reports of Wernicke's encephalopathy following pancreaticoduodenectomy

\begin{tabular}{|c|c|c|c|c|c|c|c|c|}
\hline No. & Authors & Year & Age/sex & Diagnosis/year & Op. name & Aggravating factor & Diagnosis of WE & $\mathrm{LOH}$ \\
\hline 1 & Tsujino et al. ${ }^{11}$ & 2007 & $68 / \mathrm{M}$ & $\begin{array}{l}\text { AoV cancer, } \\
1998\end{array}$ & $\mathrm{PD}$ & Loop Diuretic & 8 years after surgery & - \\
\hline 2 & da Silva et al. ${ }^{12}$ & 2010 & $28 / \mathrm{M}$ & $\begin{array}{l}\text { Duodenal ulcer } \\
\text { bleeding, } 2010\end{array}$ & WP & Pneumonia, POI & 1 week after surgery & - \\
\hline 3 & $\begin{array}{l}\text { Onieva-González } \\
\text { et al. }{ }^{13}\end{array}$ & 2011 & $27 / \mathrm{M}$ & $\begin{array}{l}\text { Duodenal ulcer } \\
\text { bleeding, } 2010\end{array}$ & PD & $\begin{array}{l}\text { Pneumonia, septic } \\
\text { shock, POI }\end{array}$ & $\begin{array}{l}\text { Several days after } \\
\text { surgery }\end{array}$ & 87 days \\
\hline 4 & $\begin{array}{l}\text { Karayiannakis } \\
\text { et al. }{ }^{14}\end{array}$ & 2011 & $52 / \mathrm{M}$ & $\begin{array}{r}\text { Pancreas head } \\
\text { cancer, } 2010\end{array}$ & WP & $\begin{array}{l}\text { Alcohol abuse, } \\
\text { POI }\end{array}$ & $\begin{array}{l}14 \text { months after } \\
\text { surgery }\end{array}$ & - \\
\hline 5 & Kilinc et al. ${ }^{15}$ & 2015 & $38 / \mathrm{F}$ & $\begin{array}{l}\text { Pancreas head } \\
\text { cancer, } 2015\end{array}$ & WP & Obstruction, POI & $\begin{array}{l}16 \text { days after } \\
\text { surgery }\end{array}$ & 31 days \\
\hline 6 & Wu et al. ${ }^{16}$ & 2017 & $45 / F$ & $\begin{array}{l}\text { Pancreas cancer, } \\
2014\end{array}$ & PD & POI & 8 weeks later & $\begin{array}{l}20 \text { days } \\
\text { over }\end{array}$ \\
\hline 7 & $\begin{array}{l}\text { AbdelRazek } \\
\text { et al. }{ }^{17}\end{array}$ & 2018 & $54 / \mathrm{M}$ & $\begin{array}{l}\text { Pancreas cancer, } \\
2015\end{array}$ & WP & - & 5 years after surgery & $\begin{array}{l}8 \text { days } \\
\text { over }\end{array}$ \\
\hline 8 & Present case & 2018 & $65 / \mathrm{M}$ & $\begin{array}{l}\text { AoV cancer, } \\
2018\end{array}$ & $\begin{array}{l}\text { Laparoscopic } \\
\text { PPPD }\end{array}$ & $\begin{array}{l}\text { Postoperative } \\
\text { bleeding, DGE, } \\
\text { POPF, POI }\end{array}$ & $\begin{array}{l}50 \text { days after } \\
\text { surgery }\end{array}$ & 73 days \\
\hline
\end{tabular}

PD, pancreaticoduodenectomy; PPPD, pylorus-preserving PD; WP, Whipple procedure; POI, poor oral intake; DGE, delayed gastric emptying; POPF, postoperative pancreatic fistula; AoV, Ampulla of Vater 
cases in which the length of the hospitalization was not reported.

WE is an acute neurological disorder resulting from a vitamin B1 (thiamine) deficiency. Thiamine is a watersoluble vitamin absorbed in the duodenum by an active mechanism, and it breaks through the blood-brain barrier by active and passive mechanisms. ${ }^{2}$ The main cause of thiamine deficiency is alcohol abuse. Among others, notable causes include chronic dietary deficiency (unbalanced diet or parenteral nutrition without thiamine), poor absorption or low intake (celiac disease, pyloric obstruction, recurrent vomiting, or gravidic hyperemesis), excessive intake of carbohydrates in relation to the supply of thiamine, and a greater need for nutrients (growth, exercise, pregnancy, or infection). ${ }^{2,3}$ The clinical presentation of the typical classic triad of ataxia, confusion, and nystagmus is present in $16-38 \%$ of patients. ${ }^{4}$

In the present case, the patient had the classic clinical triad of nystagmus, ataxia, and confusion. He had several possible causative factors for acute WE: deficiency of thiamine absorption after PPPD, long-time poor oral intake, and vomiting associated with postoperative complications. In addition, these were exacerbated by lack of supply of thiamine in long-time parenteral nutrition and increased requirement of vitamin $\mathrm{B} 1$ secondary to sepsis following grade $\mathrm{C}$-POPF.

The Nutritional support for postoperative complication patient after PPPD is the key of conservative therapy. ${ }^{5}$ Postoperative early resumption of oral intake is safe and should be encouraged within enhanced recovery protocols. ${ }^{6-9}$ In patient with POPF, There is no evidence of the benefit of avoiding oral intake in clinically stable patients. ${ }^{6}$ Grade A-POPF and stabilized Grade B-POPF can start oral intake. $^{6}$ But severe Grade B-POPF and Grade C-POPF have to avoid oral intake. ${ }^{6}$ During avoid oral intake, an artificial nutritional support is needed. ${ }^{10}$ Enteral nutrition is preferred whenever possible over parenteral nutrition. ${ }^{5}$ Nasogastric tube insertion or Nasojejunal tube insertion, feeding gastrostomy, feeding jejunostomy can be performed. ${ }^{6}$ If enteral nutrition is difficult, we can choose parenteral nutrition. For more effective parenteral nutrition, central venous catheterization is required. In addition, periodic nutritional checks is important and be supplemented with insufficient trace elements, vitamins, albumin, to prevent nutritional imbalances.
PPPD is associated with many complications and their associated DGE, which inevitably leads to long-term NPO or poor oral intake. Most of these patients have underlying sepsis, and physicians should rule out septic progression to diagnose WE when the patient has mental changes. In this case, septic progression was ruled out by follow-up abdominal CT showing evidence of decreased intra-abdominal abscesses.

In summary, postoperative acute WE is very rare, but it can develop in patients with PPPD/PD. If a patient who underwent a complicated PPPD/PD is of older age, has poor oral intake associated with a postoperative complication, or is in poor general condition, physicians must consider the possibility of acute WE when the patient experiences acute mental changes without specific reason. Serum thiamine level by itself may not be useful for diagnosis of WE, but brain MRI can be helpful.

$\mathrm{WE}$ is a rare disease, and it is difficult to detect. Left untreated, patients can progress to coma and even death. Therefore, WE needs to be considered in patients with complicated PPPD/PD associated with malnutrition.

\section{REFERENCES}

1. Yamaguchi K, Tanaka M, Chijiiwa K, Nagakawa T, Imamura M, Takada T. Early and late complications of pylorus-preserving pancreatoduodenectomy in Japan 1998. J Hepatobiliary Pancreat Surg 1999;6:303-311.

2. Reuler JB, Girard DE, Cooney TG. Current concepts. Wernicke's encephalopathy. N Engl J Med 1985;312:1035-1039.

3. Ropper AH, Samuels MA. Chapter 41. Diseases of the nervous system caused by nutritional deficiency. In: Ropper AH, Adams RD, Victor M, Samuels M, eds. Adams and Victor's principles of neurology. 9th ed. New York: McGraw-Hill Medical, 2009.

4. Sechi G, Serra A. Wernicke's encephalopathy: new clinical settings and recent advances in diagnosis and management. Lancet Neurol 2007;6:442-455.

5. Klek S, Sierzega M, Turczynowski L, Szybinski P, Szczepanek $\mathrm{K}$, Kulig J. Enteral and parenteral nutrition in the conservative treatment of pancreatic fistula: a randomized clinical trial. Gastroenterology 2011;141:157-163, 163.e1.

6. Gianotti L, Besselink MG, Sandini M, Hackert T, Conlon K, Gerritsen A, et al. Nutritional support and therapy in pancreatic surgery: a position paper of the International Study Group on Pancreatic Surgery (ISGPS). Surgery 2018;164:1035-1048.

7. Hall TC, Dennison AR, Bilku DK, Metcalfe MS, Garcea G. Enhanced recovery programmes in hepatobiliary and pancreatic surgery: a systematic review. Ann R Coll Surg Engl 2012;94: 318-326.

8. Coolsen MM, van Dam RM, van der Wilt AA, Slim K, Lassen $\mathrm{K}$, Dejong $\mathrm{CH}$. Systematic review and meta-analysis of enhanced recovery after pancreatic surgery with particular emphasis on pancreaticoduodenectomies. World J Surg 2013;37:1909-1918.

9. Kagedan DJ, Ahmed M, Devitt KS, Wei AC. Enhanced recovery 
after pancreatic surgery: a systematic review of the evidence. HPB (Oxford) 2015;17:11-16.

10. Weimann A, Braga M, Carli F, Higashiguchi T, Hübner M, Klek $\mathrm{S}$, et al. ESPEN guideline: clinical nutrition in surgery. Clin Nutr 2017:36:623-650.

11. Tsujino $T$, Nakao $S$, Wakabayashi $K$, Lee $M$, Kimura $T$, Yoshikawa $\mathrm{H}$, et al. Loop diuretic precipitated beriberi in a patient after pancreaticoduodenectomy: a case report. Am J Med Sci 2007;334:407-409.

12. da Silva JTSL, Velarde RA, Ferrero FO, Marcos MR, Civantos DP, Moreno JMR, et al. Wernicke's encephalopathy induced by total parental nutrition. Nutr Hosp 2010;25:1034-1036.

13. Onieva-González FG, Blanco-Fernández G, Munuera-Romero L, Márquez-Rojas J, Robles-Marcos M, Solórzano-Peck G. Wernicke's encephalopathy after cephalic pancreaticoduodenectomy. Rev
Esp Enferm Dig 2011;103:594-596.

14. Karayiannakis AJ, Souftas VD, Bolanaki H, Prassopoulos P, Simopoulos C. Wernicke encephalopathy after pancreaticoduodenectomy for pancreatic cancer. Pancreas 2011;40:1157-1159.

15. Kilinc O, Caferov K, Koytak PK, Gunal DI, Uluc K. Wernicke's encephalopathy in two different clinical settings: one after whipple surgery and the other due to alcohol abuse. J Neuropsychiatry Clin Neurosci 2015;27:e71-e72.

16. Wu L, Jin D, Sun X, Liang L, Huang D, Dong Z, et al. Cortical damage in Wernicke's encephalopathy with good prognosis: a report of two cases and literature review. Metab Brain Dis 2017; 32:377-384

17. AbdelRazek M, Han C, Albrecht A, Elsadek L, Yadollahikhales G, Elsadek R. Wernicke's encephalopathy 5 years after a whipple procedure. Neurohospitalist 2018;8:NP3-NP4. 